\title{
AUTOMATION AND POWER SAVING OF HOME USING ANDROID MOBILE
}

\author{
Atul V. Kamble ${ }^{1}$, Sandeep S. Bidwai ${ }^{2}$, Varsha B. Chougule ${ }^{3}$ \\ ${ }^{1}$ M.E. Student, VLSI \& Embedded System, ADCET, Ashta, Maharashtra, India \\ ${ }^{2}$ Assistant Professor, Electronics \& Telecommunication, ADCET, Ashta, Maharashtra, India \\ ${ }^{3}$ M.E. Student, VLSI \& Embedded System, ADCET, Ashta, Maharashtra, India
}

\begin{abstract}
Day by day as technology rises, varieties of electronic home appliances rises in a market. As they are useful, less time consuming and easy to use. So, people demand for these appliances increases to fulfil their needs of daily life. Sometimes, user forgot to switch off the appliances when it goes outside the home. It may consume more power or may cause damage of appliance or life of family members. To avoid these harms our aim is to develop such application which make more easy to use these appliances either user is indoor or outdoor, save the power and also the life of people mostly kids or people who require caretaker. In this we develop one application for android mobile by which we control the ON/OFF of the all-electronic appliances in home if we are indoor or outdoor, also temperature, lights of rooms, fans etc. Also security system to home, which can provide services such as central locking of all doors and windows and we can see surveillance video or image of front entrance via android application.
\end{abstract}

Keywords: Android Application, Mobile, Surveillances.

\section{INTRODUCTION}

Today's we are living in 21 st century where automation is playing important role in human life. Home automation required us to control household appliances like lamp, door, fan, heaters, air conditioner, motors etc. It not only reduce human efforts but also energy efficiency, time saving, and emergency systems to be activated. The main aim is to control appliances in critical conditions, provide security to home and to reduce the power consumption by the home electrical appliances.

Home automation is centralized control system of home electronic appliances (such as TV, washing machine, induction, Air conditioner), security, safety and power saving. Home automation is develop to provide increased quality of life for persons who need caretakers. Home automation system is automation of smart home, it includes control of lighting, temperature of rooms, heating, appliances and monitoring systems. It also include alarm system, locking of doors, windows, smoke detector, and surveillance cameras.
This paper introduce the design of system of home automation using android mobile and arduino. The model helps to control the home appliances by an android app, which is in users mobile, if user is indoor or outdoor. He/she can switch ON/OFF the electronic appliances as per the status shown by the android app. In this way user can save the family members by any problem and save the power of electricity. User can also see the view of his/her front entrance of home from anywhere outside of home on mobile by surveillance camera on the front entrance. And in this way home can prevent by thefts. He/she can lock all the doors and windows and also call police immediately. User can also save the power consumption by switch off the main supply unit of home via app, when there is nobody at home.

In figure1. Automation systems for home is shown. There is lighting control, curtains, shutter and blinds control, control of entertainment system, control of environment system like air conditioning, security system, watering system control. 


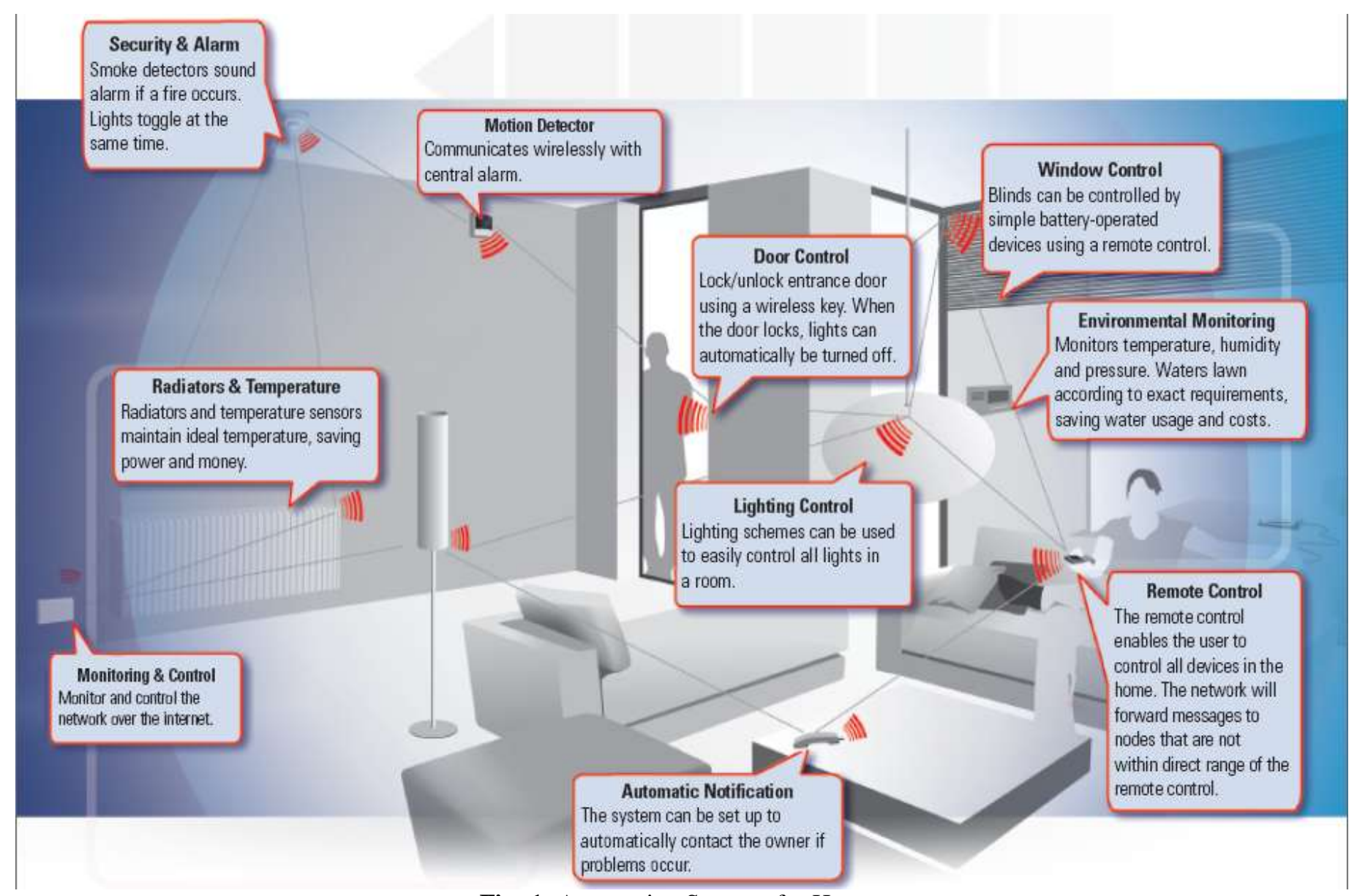

Fig- 1: Automation Systems for Home

\section{PROBLEM DEFINATION}

Due to advancement of wireless technology, there are several different connections are introduced such as bluetooth, Zig-bee etc. Various Home Automation Systems exits with cheap rate but some are difficult to install, difficult to maintain and use.Current systems are generally proprietary and closed, not very customizable by the end user.

Home automation system using Bluetooth has security but has limited range. It can use in range of 10 meters, this is the main drawback of bluetooth.

Home automation using Zig-bee overcomes the drawbacks of bluetooth but it is also lack of range.

\section{METHODOLOGY}

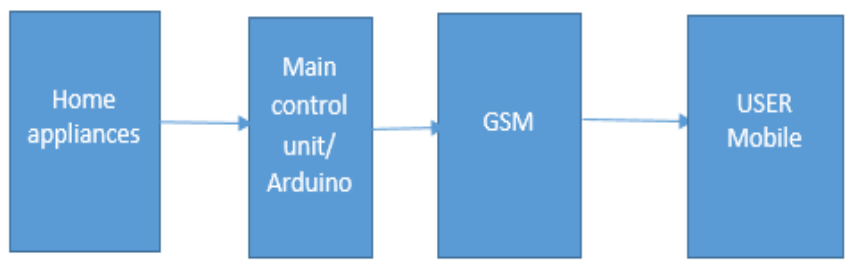

(a)

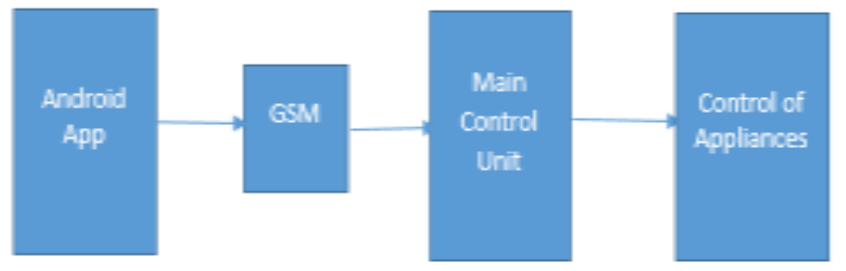

(b)

Fig-2: Hardware Loop Diagram

Figure 2(a) shows how the status of home appliances is received by user on his mobile via main control unit and GSM. So, he/she can take quick action if there is any critical condition.

Figure 2(b) shows how the response of user by knowing status of home appliances, controls the appliances. In this develop App is used by user to control the ON/OFF of the home appliances via users mobile. He/she can send the command via app, it receive by main control unit through GSM. Then according to received command and status of home electrical appliances, main control unit control the home appliances.

The home automation system consists of a set of smart phone equipment via mobile handset and GSM mobile infrastructure. Though a mobile handset user can dial the assigned number for press the key of mobile when we want to turn $\mathrm{ON}$ or $\mathrm{OFF}$ the devices that is nothing but Bluetooth 
encoded signal, that signal is fed electrical switch detection and decoding is done by Bluetooth decoder. Based upon the Arduino program, it senses which button is pressed and corresponding relay can be switched and controlled, thereby the control of devices that are connected to that particular relay can be made possible. It will also track the availability of person in room. If there isno person it switch off all the loads of that room.

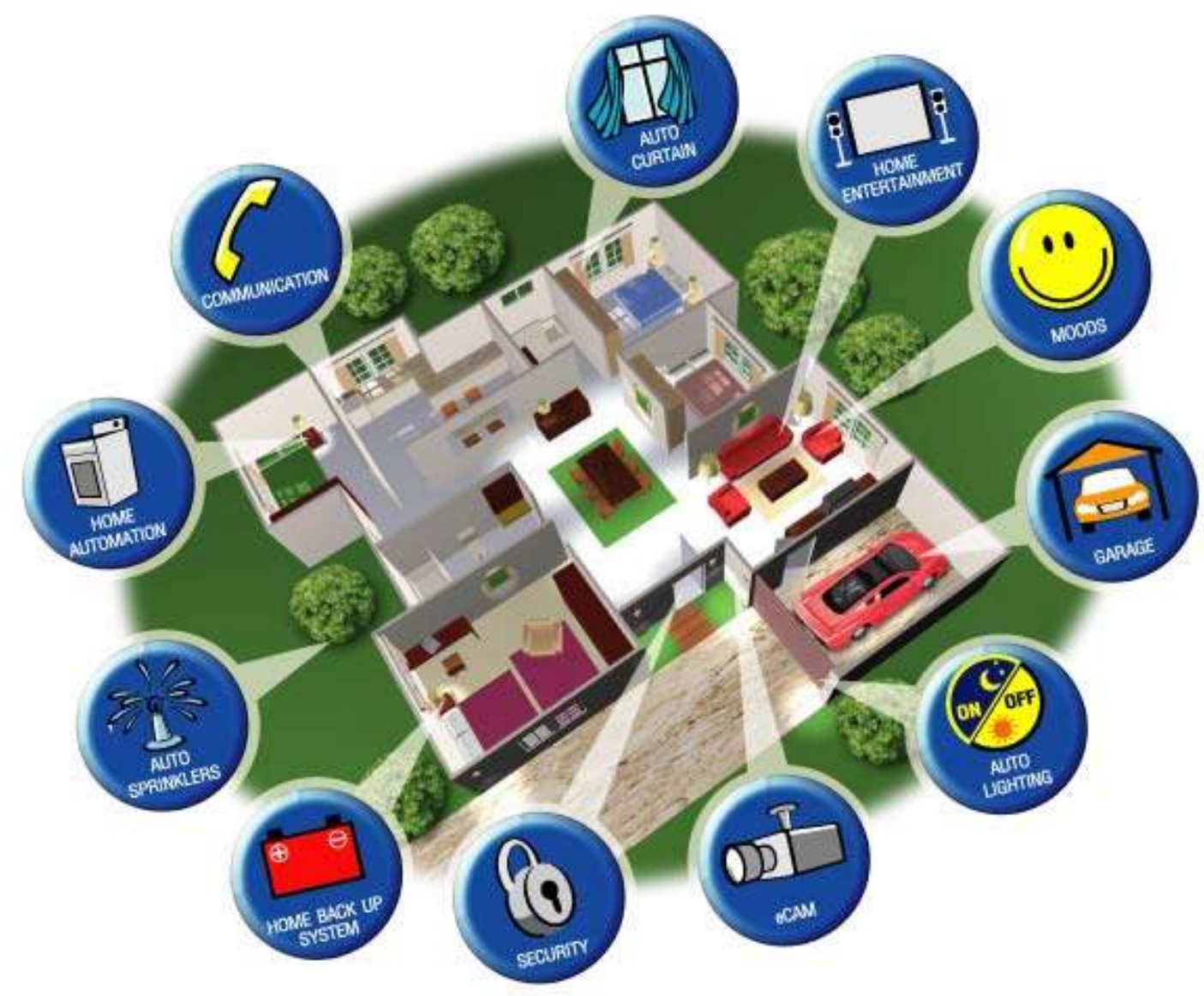

Fig-3: Home Appliances controlledby System using Android Mobile and Arduino

Figure 3 shows the home appliances those are controlled by the system using android mobile and arduino, either user is outdoor or indoor like control of water leakage, control of door and windows, control of curtains, control over place of parking, control of lights and fans of the room, control of room temperature, control over communication, control of kitchen appliances such as oven etc. Due to automation of appliances living standard of people increases as well as they can feel safe and secure. And mostly it is beneficial for handicapped or blind or elder people who needs the care takers for them all the time.

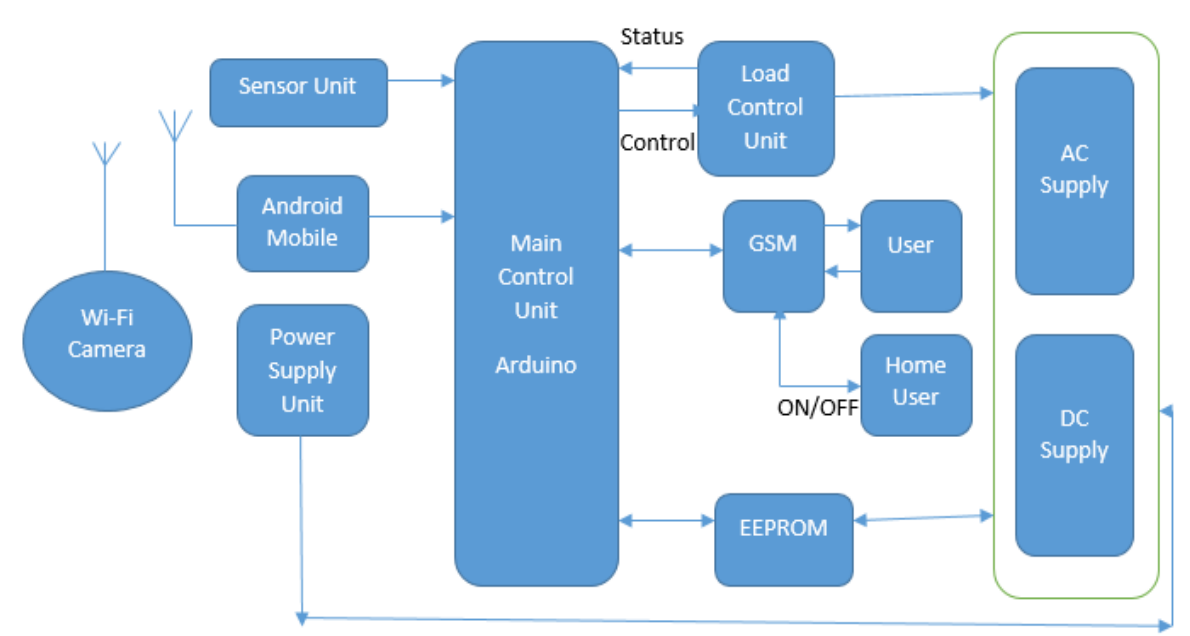

Fig-4: Conceptual Block Diagram 


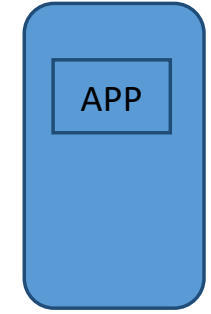

Fig-5: User Mobile

Figure 4 shows the conceptual diagram of the system. Sensor unit measures the temperature, humidity level in the home and status of the home appliances given to the main control unit i.e. Arduino. Sensors are also used to sense the smoke, fire, gas leakage, water leakage. Arduino sends the command to the user through the GSM, either to ON or OFF the appliance. User uses the Android mobile App to switch ON or OFF the home electrical appliances such as lights, fans, Air Conditioner, kitchen appliances (oven) and also the main supply, shown in figure 5. In this way power can be saved. And also lights and fans of room are OFF automatically when nobody is in room.

Wi-Fi camera is used to capture the images of the people who is in front of the entrance, continue it captures the images and send it to user mobile through GSM. So that user can know about his home.In this way, system provide security to home and home members.

Android mobile applications control the electrical home appliances, manage the schedule of devices, monitoring the devices from anywhere using mobile, keep eye on the home entrance from anywhere, doors and windows can be locked from outside of home.

EEPROM is used to save the data, so that we can analyze the data and know how much energy is saved. And also we can store the captured images by camera for future.

\section{APPLICATIONS}

- Detection of temperature, gas leakage, fire, water leakage.

- $\quad$ Safe and secure blind or elder people.

- Camera can be controlled by user to keep eye on the home.
- User can switch ON or OFF using android mobile from outdoor as well as indoor.

- Control and integration of security systems and doors and windows can be locked using android mobile.

- Control the lights, fan can save the energy and thus reduce power consumption's.

- A low voltage activating switches is replaced by current electrical switches.

- Easy to control all home appliances using single android application.

\section{CONCLUSION}

This is low cost system, easy to install and use to improve standard of living and provide security to home. Always updated status of the home electrical appliances is seen by user's android mobile.

Using home automation system user can switchon or off the home electrical appliances usinghis/her android mobile from anywhere. When there is nobody at room then lights and fansare automatically off. Hence, power is saved.

Increased quality of life who needs caretakers.Camera captures images of the entrances to user, so that user can keep eye on his/her home and also the home members.

Control of home electrical appliances and the gateway of home by mobile application provides help and assistance especially to elderly and disabled people.

\section{ACKNOWLEGEMENT}

I express my sincere thanks to everyone whosupported me for writing this review paper. I am thankful for their guidance and advice during this work. I express my warm thanks to Assistant Professor Sandeep S. Bidwai for his support and guidance at Department of Electronics and Telecommunication Engineering; Annasaheb Dange College of Engineering and Technology, Ashta, 416301; Maharashtra, India. His active cooperation and involvement have helped me to write this paper. Moreover, the great deals appreciated go to contribution of all members for valuable shares of ideas, opinions to complete this paper. 


\section{REFERENCES}

[1]. N. Sriskanthan and Tan Karand. "Bluetooth Based Home Automation System". Journal of Microprocessors and Microsystems, Vol. 26, pp.281-289, 2002

[2]. Muhammad IzarRamli, MohdHelmyAbdWahab, Nabihah. "Towards Smart Home: Control Electrical Devices Online". Nornabihah Ahmad International Conference on Science and Technology: Application in Industry and Education, 2006.

[3]. E. Yavuz, B. Hasan, I. Serkan and K. Duygu. "Safe and Secure PIC Based Remote Control Application for Intelligent Home". International Journal of Computer Science and Network Security, Vol.7, No.5, May 2007.

[4]. Shuang-hau yang and et al. "A Zigbee-based Home Automation System". IEEE Transaction, volume 55, May 2009.

[5]. Azwai F and et al. "Friendly Home Automation System using cell phone and J2ME with feedback instant voice messages". IEEE International Conference on Computational system and application, May 2009.

[6]. Raglend and et al."Home Automation using GSM". IEEE international conference, july 2011.

[7]. Pradeep.G, B.Santhi Chandra, M.Venkateswarao, "AdHoc Low Powered 802.15.1 Protocol Based Automation System for Residence using Mobile Devices", Dept. of ECE, K L University, Vijaywada, Andhra Pradesh, India IJCST Vo 1. 2, SP 1, December 2011.

[8]. R.Piyare, M.Tazil, "Bluetooth Based Home Automation System Using Cellphone", 2011 IEEE $15^{\text {th }}$ International Symposium on Consumer Electronics.

[9]. Gur and et al."An Android based Home Automation System”. IEEE Conference December 2013.

[10]. ZhanboXu and et al. "Supply Demand Coordination for Building Energy Saving", Explore the Soft Comfort. IEEE Transactions on Automation Science and Engineering, 2015. 